J. Lake Sci. (湖泊科学), 2006, 18(6):661 -669

http:// www. jlakes. org. E-mail: jlakes@ niglas. ac.cn

(c) 2006 by Journal of Lake Sciences

\title{
广东流溪河水库后生浮游动物生物量谱时空异质性
}

林秋奇, 赵帅营, 韩博平 ${ }^{* *}$

(暨南大学水生生物研究所,广州 510632)

摘 要: 于 2001 年 4 月至 2002 年 12 月调查了流溪河水库后生浮游动物, 建立后生浮游动物生物量谱并分析了其时空分 布特征. 后生浮游动物 Sheldon 型生物量谱并不是平谱, 生物量随着浮游动物粒径 (等效球体直径, ESD) 的增大而增大. 轮 虫在粒径大小范围为 $50-160 \mu \mathrm{m}$ 内生物量随着粒径的增大而减少; 枝角类 $(100-512 \mu \mathrm{m} \mathrm{ESD})$ 的生物量谱呈 “单峰型”, 最大生物量出现在中等大小的粒径组 $(200-256 \mu \mathrm{m})$. 桡足类的生物量大约占总后生浮游动物生物量的 $60 \%$, 为水库后生 浮游动物最重要的组成部分; 粒径分布范围较宽, 覆盖了轮虫和枝角类. 总体而言, 桡足类生物量随着粒径的增大而逐渐 增大. 河流区后生浮游动物标准生物量谱斜率为 -0.75 ; 湖泊区标准生物量谱斜率为 -0.58 . 在河流区, 后生浮游动物生 物量中轮虫和无节幼体所占的比例要高于湖泊区, 而湖泊区温中剑水蚤和舌状叶镖水蚤的成体和晚期桡足幼体所占的比 例高于河流区. 由于河流区小个体的优势度大于湖泊区,因此河流区后生浮游动物标准谱的斜率小于湖泊区. 从后生浮游 动物大小分布的季节性变化看,湖泊区季节性变化不明显; 河流区则变化显著,丰水期标准化谱的斜率大于 -0.75 , 枯水 期小于 -0.75 ,斜率的变化与水位波动呈正相关关系. 水库库盆的形状及水动力学的时空差异可能是影响浮游动物大小 分布时空差异的重要非生物因素之一.

关键词 : 后生浮游动物; 生物量谱; 异质性; 热带水库

\section{Spatial and temporal variation of metazooplankton biomass size spectrum in Liuxihe Reser- voir, Guangdong Province}

LIN Qiuqi, ZHAO Shuaiying \& HAN Boping

( Institute of Hydrobiology, Jinan University, Guangzhou 510632 , P. R. China)

Abstract: Spatial and temporal variation in metazooplankton biomass size spectrum was studied from April 2001 to December 2002, in a tropical reservoir, Liuxihe reservoir (South China). The SheldonWest Laketype size spectrum of metazooplankton ( 50 to $512 \mu \mathrm{m}$ equivalent spherical diameter) was not uniform, but showed an increase in biomass between successive size classes. Within rotifers $(50 \mu \mathrm{m}$ to $160 \mu \mathrm{m}$ ESD $)$, biomass decreased slightly in size, while cladoceras $(100 \mu \mathrm{m}$ to $512 \mu \mathrm{m} \mathrm{ESD})$ had maximum biomass concentration per size class at medium ranges of body size. Copepods was the most important zooplankton fraction (contributed more than $60 \%$ of total zooplankton biomass), and covered all 10 size classes from 50 to $512 \mu \mathrm{m}$ in this study. Biomass of copepods showed an overall increase in size.

As man-made lakes, reservoirs occupy an intermediate position between rivers and natural lakes by combining numerous features of rivers and lakes. Due to this unique feature, metazooplankton size distribution changed spatially in the reservoir, and the slopes of size spectra showed a different seasonal pattern between the riverine zone and the lacustrine zone. On average, small sized organisms, rotifers and nauplii, contributed a relatively more percentage biomass in the riverine zone than in the lacustrine zone, whereas adult Mesocyclops thermocyclopoids, Phyllodiaptomus tunguidus and their late stage copepodites contributed less percentage biomass in the riverine zone. As a result, the slope of normalized biomass spectrum was more negative in the riverine zone than that in the lacustrine

* 教育部“优秀青年教师资助计划”、国家自然科学基金 (39900022) 和暨南大学博士学位论文创新项目基金联合资 助. 2005-12-28 收稿;2006-06-07 收修改稿. 林秋奇,男,1973 生,博士生,讲师.

** 通讯作者; E-mail: tbphan@jnu. edu.cn. 
zone. In the riverine zone, slopes were more negative than -0.75 when water level decreased in the dry seasons and the reverse when water level increased in flood seasons. The temporal variations might be attributed to the water level fluctuation in the riverine zone. In contrast to the riverine zone, as the depth is deep enough in the lacustrine zone, and water level fluctuation showed no effect on the size distribution of metazooplankton. Size distribution of metazooplankton was relatively stable over seasons.

Keywords : Metazooplankton; size spectrum; heterogeneity; tropical reservoir

Sheldon 等人于 1972 年首次报导了海洋生物的生物量谱 ( 又称粒径谱),并发现海洋生物的生物量谱谱 型是平谱, 即生物量在各粒径组中是均匀分布的 ${ }^{[1]}$. 该生物量谱把生物有机体的大小 (等效球体直径) 分为 一系列连续的粒径组,每一组等效球体直径的上限对应的球体体积是下限的两倍,然后在以 2 为基底的对 数横坐标轴上, 以每一粒径组的下限为横坐标, 对应该粒径组的生物有机体的总生物量为纵坐标而构建出 来. 此后,生物量谱法越来越多被应用到水域生态系统的结构与功能的研究中 ${ }^{[2,3]}$. 在群落水平上, 谱型的 变化可以反映群落结构的季节性变化和空间变化 ${ }^{[4,5]}$. Cyr and Pace 研究了北美 28 座湖泊后生浮游动物群 落生物量谱特征, 发现谱型在不同湖泊之间变化比较大,而且谱型的变化与湖泊的形态结构密切相关 ${ }^{[6,7]}$.

水库作为一种半人工半自然的水体,其形态结构有别于自然湖泊 ${ }^{[8,9]}$. 由于水库库盆的几何形状和水 流速的纵向变化, 导致水库从人河流人水库处到大坝在物理和化学上有较为明显的梯度分布, 影响了浮游 生物在水库中的空间分布 ${ }^{[8,10]}$. 与此同时,水库水文循环的季节性变化也可以影响浮游生物在水库中的时 空分布 ${ }^{[11,12]}$. 有关这些理化纵向梯度以及水文特征的季节性变化是否导致水库后生浮游动物群落的生物 量谱存在时空异质性报导很少. 针对以上问题, 本文以地处热带地区北缘的水库一一流溪河水库为研究对 象, 构建和分析了后生浮游动物群落生物量谱的时空分布特征. 流溪河水库介绍详见林秋奇等 ${ }^{[12]}$.

\section{1 材料与方法}

根据流溪河水库水流特征, 在两条主要河流吕田河 (S1) 和玉溪河 (S2) 人库口处, 库中 (S3) 和大坝处 (S4) 设置四个采样点 (图 1). 于 2001 年 4 月至 2002 年 12 月每隔 2 或 3 个月对水库进行采样. 用萨氏盘测 定透明度. 后生浮游动物定量样品用 $5 \mathrm{~L}$ 采水器从表层 $0.5 \mathrm{~m}$ 处每隔 $1 \mathrm{~m}$ 采至 $10 \mathrm{~m}$ (湖泊区真光层) 或从表 层 $0.5 \mathrm{~m}$ 处每隔 $1 \mathrm{~m}$ 采至底层 $0.5 \mathrm{~m}$ 处, 用 $30 \mu \mathrm{m}$ 浮游生物网当场过滤, 用福尔马林固定 $(5 \%)$. 对后生浮 游动物计数的同时, 测量每个个体的大小. 其中, 轮虫的体积通过测定体长和体宽, 采用近似几何体积公式 计算 ${ }^{[13]}$; 甲壳类的湿重则通过测定体长, 采用体长与体重的几何异速方程计算 ${ }^{[13,14]}$. 浮游动物的比重近似 为 1 . 采用 Sheldon 型生物量谱方法构建流溪河水库后生浮游动物生物量谱和标准密度谱 ${ }^{[1,15,16]}$. 流溪河水 库后生浮游动物个体大小的等效球体直径 (ESD, equivalent spherical diameter) (即体积相同的球体直径)

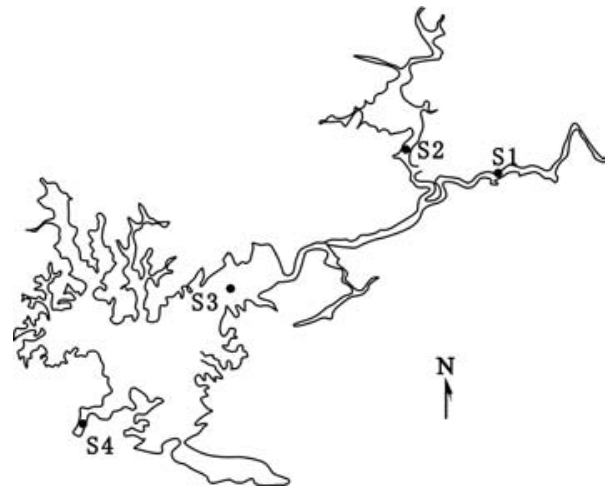

图 1 流溪河水库中采样点位置

Fig. 1 Sampling sites in Liuxihe Reservoir 为 $50-512 \mu \mathrm{m}$, 分为 10 个连续的粒径组: $50.0-64.0 \mu \mathrm{m}$ 、 $64.0-80.6 \mu \mathrm{m} 、 80.6-101.6 \mu \mathrm{m} 、 101.6-128.0 \mu \mathrm{m} 、 128.0$ $-161.3 \mu \mathrm{m} 、 161.3-203.2 \mu \mathrm{m} 、 203.2-256.0 \mu \mathrm{m} 、 256.0-$ $322.5 \mu \mathrm{m} 、 322.5-406.4 \mu \mathrm{m}$ 和 $406.4-512.0 \mu \mathrm{m}$, 每一组 ESD 的上限对应的体积是下限的两倍. 在以 2 为基底的对 数横坐标轴上, 以每一组个体大小 ( ESD) 的下限为横坐标, 对应该组的后生浮游动物生物量为纵坐标, 构建了 Sheldon 型生物量谱. 生物量标准谱的构建则是以每一组 ESD 的下 限对应的生物量的对数值 (以 2 为基底) 为横坐标, 以该组 的后生浮游动物生物量除以该组对应粒径体积的对数值 (以 2 为基底) 为纵坐标. 生物量标准谱回归方程的斜率反 映了后生浮游动物生物量在不同粒径组的分布情况. 流溪 河水库水文数据由流溪河水电站提供. 为了更好地反映流 溪河水库后生浮游动物大小组成的季节性变化,将 2001 年 
4 月 - 2002 年 12 月按流域水文循环特征可大致分为四个时期:2001 年丰水期 (4 - 9 月)、2001 年枯水期 (10-12 月)、2002 年丰水期 (4 - 9 月)和 2002 年枯水期( $1-3$ 月和 10-12 月). 采用 SPSS 统计分析软件对 数据进行单因素方差分析.
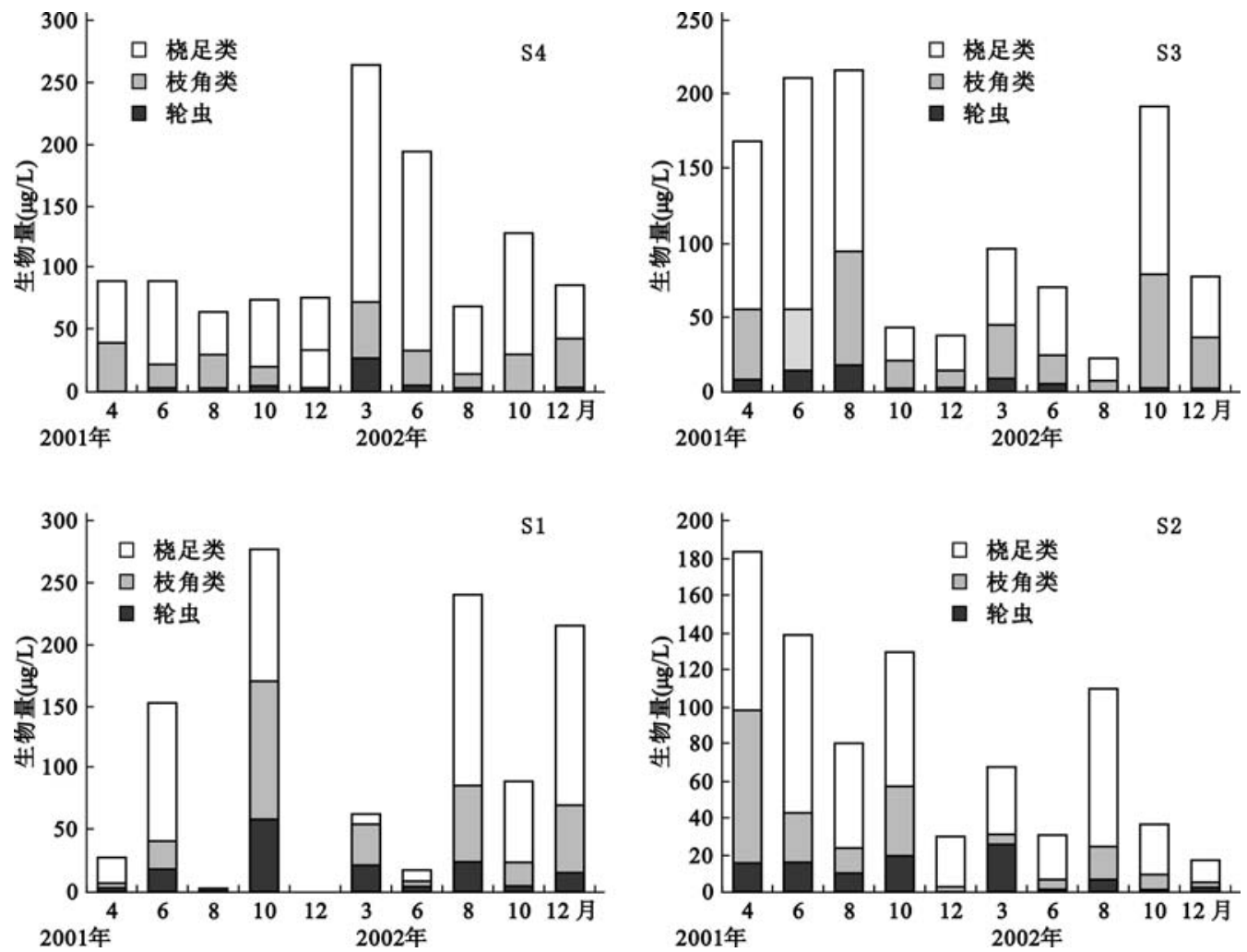

图 2 后生浮游动物生物量的时空变化

Fig. 2 Temporal and spatial variations of metazooplankton biomass

\section{2 结果与讨论}

\section{1 后生浮游动物组成特征}

轮虫、枝角类和桡足类生物量分别为 $0.04-25.43 、 0.09-82.67$ 和 $0.17-191.07 \mu \mathrm{g} / \mathrm{L}$. 在各采样点,桡 足类占总后生浮游动物生物量的 $60 \%$ 以上, 并且以无节幼体和桡足幼体为优势 (图 2). 吕田河后生浮游动 物生物量显著低于其它 3 个采样点 $\left(F_{3,34}=3.975, P=0.016\right)$; 玉溪河后生浮游动物生物量与大坝和库中 2 个采样点差异不显著 $\left(F_{2,27}=0.766, P=0.475\right)$. 各采样点后生浮游动物生物量季节性变化不明显. 轮虫以 螺形龟甲轮虫 (Keratella cochlearis)、广生多肢轮虫 (Polyarthra vulgaris)、较大多肢轮虫 ( P. major)、胶鞘轮虫 (Collotheca) 和病毛轮虫 (Synchaeta) 为优势种. 枝角类丰水期以短尾秀体溞 (Diaphanosoma brachyurum) 为主 要优势种,枯水期以脆弱象鼻溞 (Bosmina fatalis) 为优势种. 桡足类成体丰度一般不超过 $10 \mathrm{ind} . / L$, 并以温 中剑水蚤 (Mesocyclops thermocyclopoides) 和微小近剑水蚤( Tropocyclops parvus) 为主.

大坝与库中 $\left(F_{1,19}=0.898, P=0.356\right)$ 、两个河流采样点 $\left(F_{1,17}=0.036, P=0.853\right)$ 间后生浮游动 物大小分布特征较为相似, 为了更好地反映流溪河水库后生浮游动物大小组成的空间变化, 将大坝和库中 数据合并代表湖泊区,玉溪河和吕田河的数据合并代表河流区. 图 3 给出了湖泊区和河流区在四个水文时 期后生浮游动物大小组成. 在后生浮游动物生物量中, 河流区轮虫所占的比例要高于湖泊区 $\left(F_{1,36}=\right.$ 

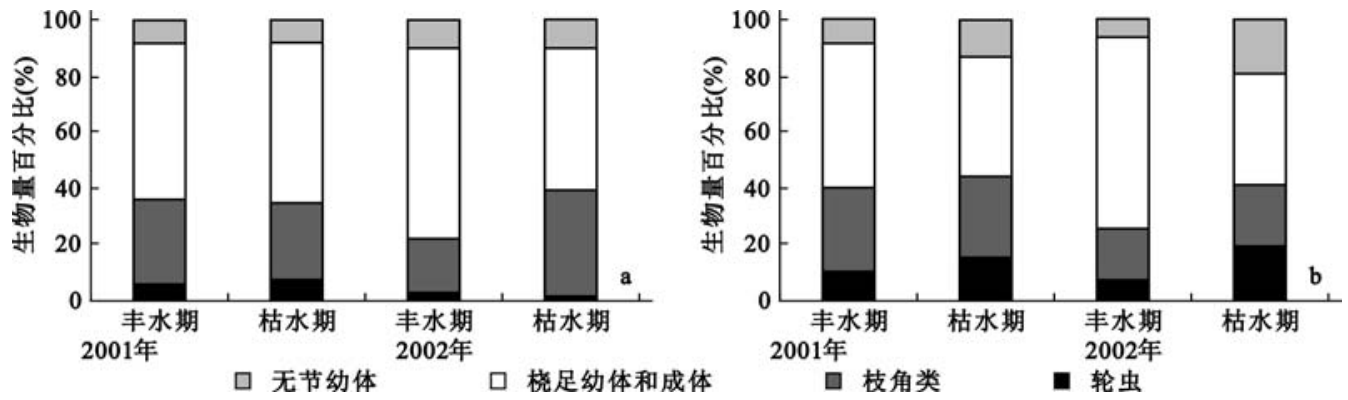

图 3 湖泊区 ( a ) 和河流区 (b) 后生浮游动物生物量相对组成

Fig. 3 Relative biomass of metazooplankton in the lacustrine zone (a) and the riverine zone (b)

13. $81, P=0.001)$; 而在湖泊区舌状叶镖水蚤的成体和晚期桡足幼体所占的比例高于河流区 $\left(F_{1,36}=\right.$ 4. 31, $P=0.045)$. 在湖泊区, 轮虫和桡足类无节幼体这些小个体所占的生物量百分比在丰、枯两水期间差 异不显著 $\left(F_{1,18}=0.313, P=0.583\right)$. 在河流区,枯水期轮虫和桡足类无节幼体这些生物量谱中粒径最小 的个体所占的生物量百分比明显高于丰水期 $\left(F_{1,16}=9.824, P=0.006\right)$; 但个体较大的温中剑水蚤和舌状 叶镖水蚤的成体和桡足幼体所占的生物量百分比小于丰水期 $\left(F_{1,16}=13.128, P=0.002\right)$.

\section{2 后生浮游动物总的生物量谱}

由图 4a 可见, 流溪河水库后生浮游动物个体大小 (等效球形直径, ESD) 范围为 $50-512 \mu \mathrm{m}$, 生物量在 各个等效直径组不是均匀分布的, 而是随着粒径大小的增大而增加. 后生浮游动物 Sheldon 型生物量谱可被 分解为 3 个相互重叠的部分: 轮虫、枝角类和桡足类, 但它们的分布特征并不相同. 轮虫大小范围为 $50-$ $160 \mu \mathrm{m} \mathrm{ESD}$,生物量随着等效直径的增大而减少. 在最小的等效直径组中,主要是螺形龟甲轮虫和广生多肢 轮虫; 在最大的等效直径组中, 主要是郝氏坡甲轮虫 (Ploesoma hudsoni) 和前节晶囊轮虫 (Asplanchna priodon-

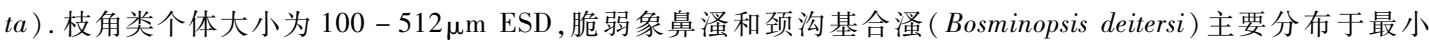
的等效直径组,而透明溞 (Daphnia hyalina) 分布于最大的等效直径组. 枝角类生物量大小分布模式呈 “单峰 型, 最大生物量出现在中等大小的等效直径组 $(200-256 \mu \mathrm{m})$, 分布在这个等效直径组的枝角类主要是短 尾秀体溞. 桡足类是流溪河水库浮游动物生物量最重要的组成部分, 个体大小分布覆盖了轮虫和枝角类的 粒径范围. 最大的等效直径组是舌状叶镖水蚤 (Phyllodiaptomus tunguidus) 的成体及其晚期的桡足幼体; 最 小等效直径组的是无节幼体; 介于它们之间的是剑水蚤 (微小近剑水蚤和温中剑水蚤) 和舌状叶镖水蚤的

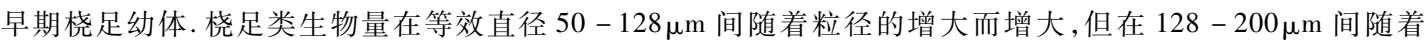
粒径的增大而减少,然后在 $200-512 \mu \mathrm{m}$ 又随着粒径的增大而增大. 分布在等效直径 $128-200 \mu \mathrm{m}$ 范围内的 桡足类主要是舌状叶镖水蚤的第六无节幼体及其早期桡足幼体、近剑水蚤的桡足幼体及成体和中剑水蚤的 桡足幼体.

流溪河水库后生浮游动物标准化生物量谱回归线的斜率是 -0.65 (图 4b). 一般认为,发育良好的自然 动物群落 (主要来自陆地生态系统) 的标准化谱是一个线性谱 ${ }^{[17-19]}$, 而且线性回归的斜率接近 -0.75 ${ }^{[17,20]}$. 流溪河水库后生浮游动物的标准化谱是一个线性谱 (图 $4 b$ ), 但斜率大于 -0.75 , 不同于温带地区湖 泊 ${ }^{[6,21]}$. Cyr 和 Pace 调查了北美 28 个湖泊浮游动物的生物量谱谱型, 发现 $77 \%$ 以上的浮游动物群落的标 准化谱并不是线性的, 呈 “双峰”型 ${ }^{[6]}$. 在其它温带湖泊, 如 Constance 湖 ${ }^{[22]}$ 和 Ciso 湖 ${ }^{[23]}$, 浮游动物标准化谱 虽呈线性,但斜率接近于 -0.75 或小于 -0.75 . 相对于温带地区, 热带地区水体浮游动物种类多样性要低 一些 ${ }^{[24,25]}$. Sprules 认为较低的浮游动物多样性通常易造成谱型成锯齿状 ${ }^{[26]}$. 在流溪河水库, 桡足类全年均 能生殖, 桡足类无节幼体和携卵雌体在水库中全年均有分布, 桡足类在各个等效直径组均有分布. 桡足类生 物量在等效直径 $50-128 \mu \mathrm{m}$ 和 $200-512 \mu \mathrm{m}$ 间均随着粒径的增大而增大; 虽然在 $128-200 \mu \mathrm{m}$ 间随着粒径 的增大而减少, 但在此范围枝角类生物量刚好随着粒径的增大而增大 (图 $4 \mathrm{a}$ ). 因此, 后生浮游动物生物量 谱谱型并不是锯齿状的,而是比较平滑地线性递增. 

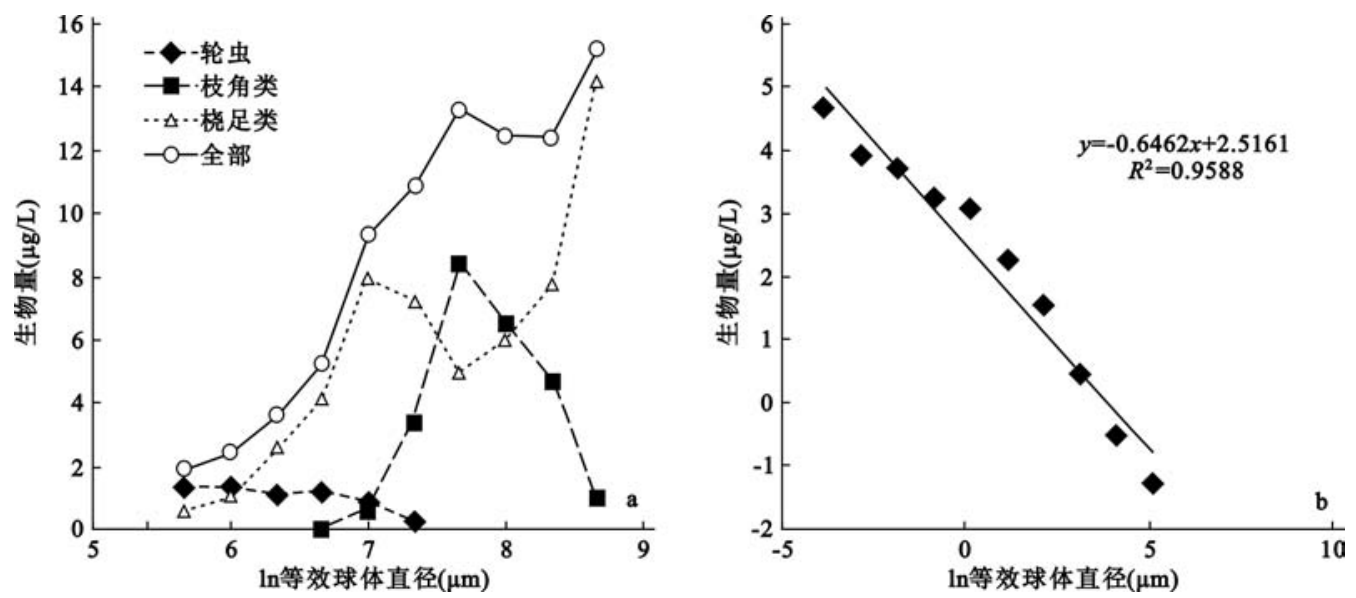

图 4 流溪河水库 Sheldon 型后生浮游动物生物量谱 ( a) 和标准化生物量谱 ( b)

Fig. 4 Sheldon-type spectrum (a) and the normalized biomass spectra

(b) of metazooplankton assemblage in Liuxihe Reservoir

表 1 后生浮游动物标准谱参数和水库水位波动 (采样当天水位与半个月前水位差值)

Tab. 1 Parameters of the normalized biomass spectra and water level fluctuations

\begin{tabular}{|c|c|c|c|c|c|c|c|c|c|c|c|}
\hline & \multicolumn{3}{|c|}{2001 年丰水期 } & \multicolumn{3}{|c|}{$2001-2002$ 年枯水期 } & \multicolumn{2}{|c|}{2002 年丰水期 } & \multicolumn{2}{|c|}{2002 年枯水期 } \\
\hline & & 4 月 & 6 月 & 8 月 & 10 月 & 12 月 & 3 月 & 6 月 & 8 月 & 10 月 & 12 月 \\
\hline \multirow{3}{*}{ 大坝 } & 截距 & 2.36 & 2.36 & 1.88 & 2.58 & 1.91 & 3.91 & 3.43 & 1.89 & 2.33 & 2.08 \\
\hline & 斜率 & -0.60 & -0.56 & -0.63 & -0.62 & -0.57 & -0.62 & -0.55 & -0.52 & -0.52 & -0.54 \\
\hline & $R^{2}$ & 0.86 & 0.89 & 0.84 & 0.87 & 0.94 & 0.88 & 0.85 & 0.93 & 0.81 & 0.89 \\
\hline \multirow[t]{3}{*}{ 库中 } & 截距 & 3.14 & 3.71 & 3.79 & 1.49 & 1.31 & 2.45 & 2.03 & 0.44 & 3.49 & 2.03 \\
\hline & 斜率 & -0.55 & -0.59 & -0.65 & -0.68 & -0.63 & -0.55 & -0.57 & -0.60 & -0.56 & -0.54 \\
\hline & $R^{2}$ & 0.88 & 0.93 & 0.91 & 0.89 & 0.96 & 0.86 & 0.81 & 0.90 & 0.91 & 0.92 \\
\hline \multicolumn{2}{|c|}{ 玉溪河截距 } & 3.27 & 3.11 & 2.92 & 3.57 & 1.06 & 2.47 & 0.32 & 2.76 & 1.45 & 0.43 \\
\hline & 斜率 & -0.55 & -0.63 & -0.80 & -0.90 & -0.75 & -0.91 & -0.54 & -0.63 & -0.80 & -0.89 \\
\hline & $R^{2}$ & 0.94 & 0.96 & 0.91 & 0.89 & 0.88 & 0.92 & 0.96 & 0.86 & 0.89 & 0.91 \\
\hline 吕田河 & 截距 & -1.29 & 1.02 & -4.50 & 2.21 & - & 0.33 & -1.88 & 1.75 & 0.45 & 1.10 \\
\hline & 斜率 & -0.51 & -0.66 & -0.84 & -0.90 & - & -0.86 & -0.59 & -0.72 & -0.84 & -0.85 \\
\hline & $R^{2}$ & 0.98 & 0.95 & 0.89 & 0.92 & - & 0.95 & 0.82 & 0.91 & 0.90 & 0.90 \\
\hline k位波云 & 动 $(\mathrm{m})$ & 1.80 & 1.70 & -0.85 & -1.00 & 0.70 & -0.92 & 1.27 & 0.17 & -0.16 & -0.81 \\
\hline
\end{tabular}

* - 为样品丢失

\section{3 后生浮游动物生物量谱的空间差异}

在湖泊区, 库中和大坝两个采样点后生浮游动物标准化生物量谱的斜率均没有显著差异 $\left(\right.$ 表 $1, F_{1,19}=$ $0.898, P=0.356)$, 因此把这两个样点的数据合并,代表湖泊区,对应标准化谱见表 2 , 图 5 ; 尽管玉溪河后 生浮游动物标准化谱的截距大于吕田河, 但其斜率并没有显著差异 (表 $1, F_{1,17}=0.036, P=0.853$ ) 同样把 吕田河和玉溪河的数据合并代表整个河流区 (表 2 和图 5 ). 如果标准化谱的斜率为 -0.75 , 表示在食物链 能量流动过程中, 各个等效粒径组消耗的能量是相等的 ${ }^{[17,20,27]}$. 从后生浮游动物标准化谱的空间差异看, 湖泊区标准化谱斜率 $(-0.58)$ 明显大于 -0.75 , 在食物链能量流动过程中,大个体比小个体消耗了更多的 
能量;河流区的斜率接近 -0.75 , 各个等效直径组后生浮游动物消耗的能量是相等的.

由图 3 可见,在后生浮游动物生物量中, 河流区轮虫和无节幼体所占的比例要高于湖泊区;而湖泊区温 中剑水蚤和舌状叶镖水蚤的成体和桡足幼体所占的比例高于河流区. 由于河流区小个体后生浮游动物的优 势度大于湖泊区,因此标准谱的斜率小于湖泊区. 水体营养水平、水深和外部扰动可直接或间接影响后生浮 游生物生物量谱的谱型 ${ }^{[5,16,22,28,29]}$. 流溪河水库建于河流峡谷中, 河流区窄浅、流速较快, 而湖泊区宽深、水 流缓慢. 河流区较快的水流流速使得食物链能量流动过程中上一营养级的能量向后生浮游动物传递的效率 低于水流缓慢的湖泊区. 水库水动力学过程的空间差异很可能是造成河流区后生浮游动物谱型斜率小湖泊 区的原因之一.

表 2 后生浮游动物标准谱参数的季节性变化

Tab. 2 Seasonal changes in parameters of the normalized biomass spectra

\begin{tabular}{|c|c|c|c|c|c|c|}
\hline & & \multicolumn{2}{|c|}{2001 年 } & \multicolumn{2}{|c|}{2002 年 } & \multirow{2}{*}{ 总体 } \\
\hline & & 丰水期 & 枯水期 & 丰水期 & 枯水期 & \\
\hline \multirow[t]{3}{*}{ 湖泊区 } & 截距 & 3.13 & 2.63 & 2.36 & 2.64 & 2.79 \\
\hline & 斜率 & -0.60 & -0.61 & -0.55 & -0.58 & -0.58 \\
\hline & $R^{2}$ & 0.92 & 0.95 & 0.88 & 0.91 & 0.94 \\
\hline \multirow[t]{3}{*}{ 河流区 } & 截距 & 2.58 & 2.50 & 1.58 & 0.97 & 2.13 \\
\hline & 斜率 & -0.66 & -0.85 & -0.64 & -0.83 & -0.76 \\
\hline & $R^{2}$ & 0.99 & 0.95 & 0.91 & 0.92 & 0.97 \\
\hline
\end{tabular}

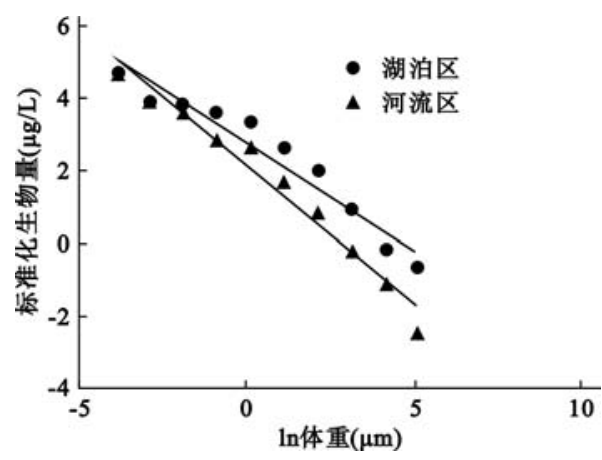

图 5 河流区和湖泊区后生浮游动物标准化谱

Fig. 5 Horizontal variability of normalized spectra

\section{4 后生浮游动物生物量谱的季节性变化}

从后生浮游动物标准化生物量谱的季节变化看, 湖泊 区后生浮游动物标准化谱呈线性,但各次采样期间斜率差 异不显著, 后生浮游动物的生物量谱谱型没有季节性变 化; 河流区的吕田河和玉溪河的谱型也均呈线性, 而且在 各次采样期间斜率有明显的波动 (表 1). 河流区四个水文 时期的后生浮游动物标准化生物量谱的谱型见图 6. 在枯 水期, 轮虫和桡足类无节幼体这些生物量谱中等效直径最 小的个体所占的生物量百分比明显高于丰水期; 但等效直 径较大的温中剑水蚤和舌状叶镖水蚤的成体和桡足幼体 所占的生物量百分比小于丰水期 (图 5). 因此, 枯水期浮游 动物标准化生物量谱斜率明显小于丰水期.

温度是引起温带湖泊浮游动物季节性分布的一个重 要因素 ${ }^{[30]}$. 从春季到早夏, 小个体生物量百分比逐渐减少, 大个体生物量百分比则逐渐增多 ${ }^{[22]}$. 流溪河水 库地处热带地区北缘,调查期间表层水温为 $18-31^{\circ} \mathrm{C}$, 水温波动幅度仍然比较明显. 河流区和湖泊区浮游动 物标准谱的斜率的变化均与温度相关性不显著. 这很可能由于温度与其它非生物和生物因素 (水动力学、 捕食等) 存在内在联系, 温度对浮游动物的影响受其它因素的掩盖而不易直接观察到 ${ }^{[31]}$. 因此, 温度对流溪 河水库后生浮游动物生物量谱的影响还有待进一步探讨.

受流域水文循环和出库水流的人为调节,水库水位有明显的季节性上下波动. 在丰水期水库水位上涨 时, 吕田河和玉溪河后生浮游动物标准化生物量谱的斜率明显大于 -0.75 , 在枯水期水位下降时, 斜率小于 -0.75 , 斜率与水库水位波动均呈显著的正相关关系 (图 7). Cyr 和 Peters 比较了温带地区 24 座不同水面 面积和水深的湖泊和水库的浮游生物群落的生物量谱, 发现生物量谱谱型的变化与水体的形态结构密切相 关,标准化生物量谱斜率随着湖泊水面面积和水深的增大而减小 ${ }^{[7]}$. Brandorff 和 De Adndrade 发现水体水 位的波动可影响后生浮游动物的生活史 ${ }^{[32]}$, 从而影响后生浮游动物个体大小的分布特征. 流溪河水库为峡 谷型水库,河流区不仅窄浅, 人库流量和出库流量之间的交换使得水库水位的波动比较频繁, 水位波动对河 


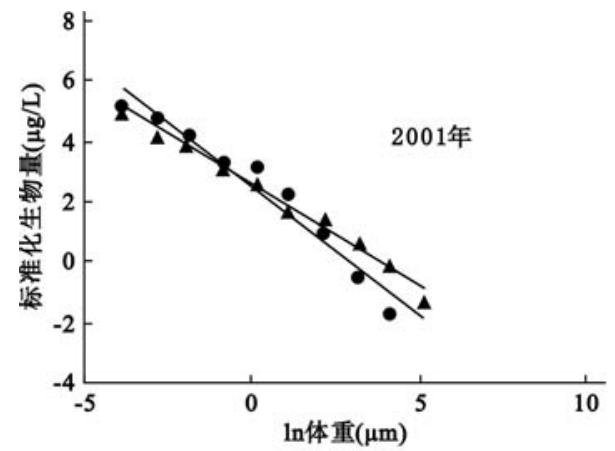

、丰水期

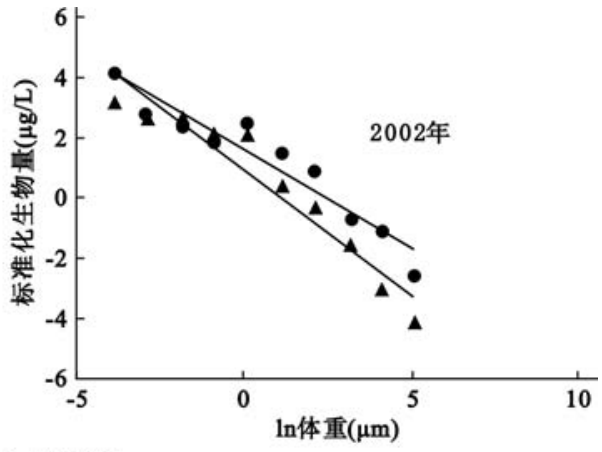

- 枯水期

图 6 河流区浮游动物标准化谱的季节性变化

Fig. 6 Seasonal variability of normalized spectra from riverine zone
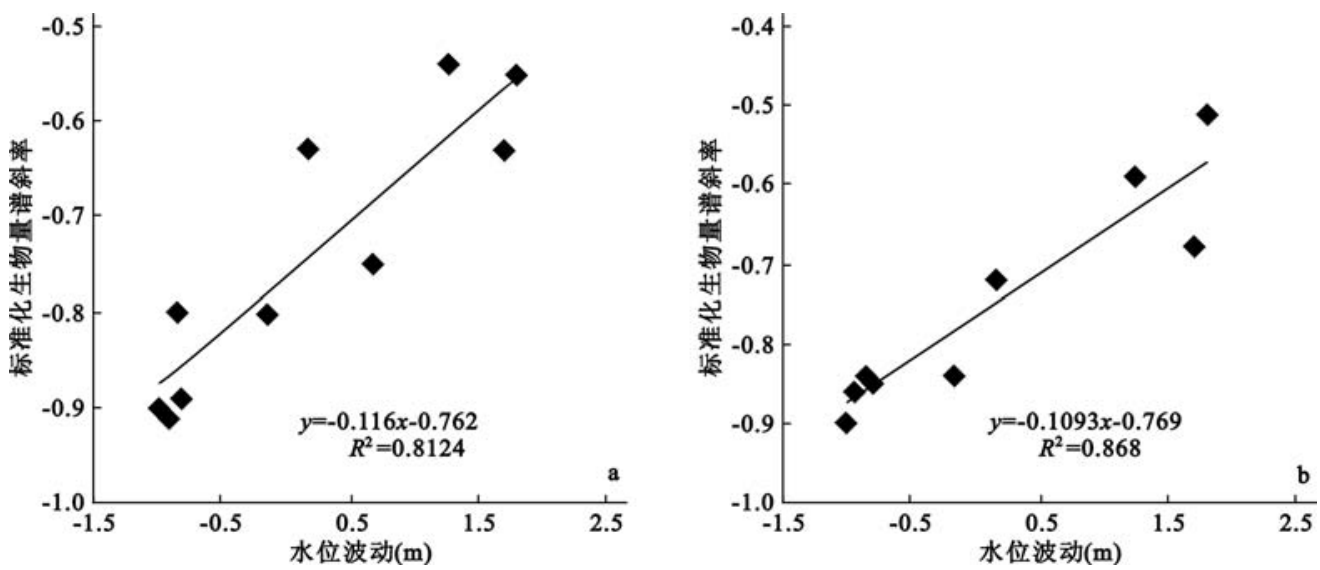

图 7 玉溪河 (a) 和吕田河 (b) 浮游动物标准化生物量谱斜率与水位波动关系

Fig. 7 Relationship between slope of the normalized biomass spectra and water level fluctuation in the Yuxi River (a) and the Lutian River (b)

流区水面面积和水深影响甚大. 丰水期, 人库流量大于出库流量时, 水库水位上涨, 河流区水面面积和水深 均增大, 食物链能量流动传递效率相对比较高, 后生浮游动物标准谱的斜率相对比较低; 枯水期, 人库流量 小于出库流量时, 水库水位下降, 河流区水面面积和水深均下降, 食物链能量流动传递效率相对比较低, 后 生浮游动物生物量谱标准谱的斜率大于丰水期时. 不同于河流区, 湖泊区后生浮游动物标准化谱的斜率与 水位波动没有显著的相关性. 由于流溪河水库平均水深达 $23.5 \mathrm{~m}$, 而且湖泊区远比河流区深得多,最深处可 达 60 多米,水位波动对湖泊区水深影响几乎可以忽略不计,与此同时,库岸陡峭,水位波动导致湖泊区水面 面积的变化较小, 水位波动对后生浮游动物生活史的影响不大. 从以上分析可见,水库库盆的形状及水动力 学的时空差异可能是影响浮游动物大小分布时空差异的重要非生物因素之一.

\section{3 结论}


个体的优势度大于湖泊区. 湖泊区生物量谱的季节性变化不明显; 河流区则季节性变化显著,枯水期小个体 的优势度大于丰水期,造成标准化谱斜率枯水期小于丰水期. 水库库盆的形态及水动力学的时空差异可能 是影响浮游动物大小分布时空差异的重要非生物因素之一.

\section{4 参考文献}

[1] Sheldon R W, A Prakash \& Sutcliffe W H. The size distribution of particles in the ocean. Limnol Oceanogr, $1972,17: 327-340$.

[2] Han B P \& Straš Kraba M. Size dependence of biomass spectra and population density I. The effects of size scales and size intervals. J Theor Biol, 1998, 191: $259-265$.

[3] Han B P \& Straš Kraba M. Reanalysis of models and an improved model of biomass size spectra. Internat Rev Hydrobiol, 1999, 83(3):207-231.

[4] Echevarria F \& Rodriguez J. The size structure of plankton during a deep bloom in a stratified reservoir. Hydrobiologia, 1994, 284 : 113 - 124.

[5] Wen Y H. Hydrographic variations in size structure of plankton biomass in a Changjiang floodplain lake. Arch Hydrobiol, 1995 ,132(4) : 427 - 435.

[6] Cyr H \& Pace M L. Allometric theory: extrapolations from individuals to communities. Ecology, 1993, 74 (4) : $1234-1245$.

[7] Cyr H \& Peters R H. Biomass-size spectra and the prediction of fish biomass in lakes. Can J Fish Aquat. Sci, 1996, 53: $994-1006$.

[8] Thornton K W. Perspectives on Reservoir Limnology. In: Thornton K W, Kimmel B L \& Payne F E eds. Reservoir limnology : Ecological perspectives. New York : John Wiley \& Sons Inc, 1990.

[9] Straskraba M, Tundisi J G \& Ducan A. State-of-the-art of reservoir limnology and water quality management. In: Straškraba M, Tundisi J G \& Duncan A eds. Comparative reservoir limnology and water quality management. The Netherlands: Kluwer Academic Pubishers, 1993.

[10] Marzolf G R. Reservoirs as environments for zooplankton. In: Thornton K W, Kimmel B L \& Payne F E eds, Reservoir limnology: Ecological perspectives. New York : John Wiley \& Sons Inc, 1990.

[11] Nilssen J P. Tropical lakes-functional ecology and future development: The need for a process-orientated approach. Hydrobiologia, 1984, 113 : $231-242$.

[12] 林秋奇, 胡 韧, 韩博平. 流溪河水库水动力对营养盐和浮游植物分布的影响. 生态学报, 2003,23 (11) :2278-2284.

[13] 章宗涉,黄祥飞. 淡水浮游生物研究方法. 北京:科学出版社,1991.

[14] 陈雪梅. 淡水桡足类生物量的测算. 水生生物学集刊,1981,7(3):397-408.

[15] Platt T \& Denman K. The structure of pelagic marine ecosystem. Helgol Wiss Meeresunters, 1978, 30 : 575 581.

[16] Sprules W G \& Munawar M. Plankton size spectra in relation to ecosystem productivity, size, and perturbation. Can J Fish Aquat Sci, 1986,43 : 1761 - 1769.

[17] Damuth J. Interspecific allometry of population density in mammals and other animals: the independence of body mass and population energy use. Biol J Linn Soc, 1987,31: 193 - 246.

[18] Gaston K J \& Lawton J H. Patterns in the distribution and abundance of insect populations. Nature, 1988, 331 : $709-712$.

[19] Peters R H \& Wassenberg K. The effect of body size on animal abundance. Oecologia, 1983,60 : 89 - 96.

[20] Damuth J. Population density and body size in mammals. Nature, 1981,290:699- 700.

[21] Havlicek T D \& Carpenter S R. Pelagic species size distribution in lakes: Are they discontinuous? Limnol Oceanogr, 2001,46(5) : 1021 - 1033. 
[22] Gaedke U. The size distribution of plankton biomass in a large lake and its seasonal variability. Limnol Oceanogr, $1992, \mathbf{3 7}(6)$ : $1202-1220$.

[23] Gasol J M, Guerrero R \& Peraos-Alio C. Seasonal variations in size structure and prokaryotic dominance in sulfurous Lake Ciso. Limnol Oceanogr, 1991,36(5) : 860 - 872.

[24] Fernando C H. The freshwater zooplankton of Sri Lanka with a discussion of tropical freshwater zooplankton composition. Int Revue Ges Hydrobiol, 1980,65: 85 - 125.

[25] Fernando $\mathrm{C} \mathrm{H}$. The species and size composition of tropical freshwater zooplankton, with special reference to the Oriental Region (South East Asia). Int Revue Ges Hydrobiol, 1980,65: 411 - 426.

[26] Sprules W G. Effects of trophic interactions on the shape of pelagic size spectra. Verh Internat Verein Limnol, 1988, 23: $234-240$.

[27] Damuth J. Of size and abundance. Nature, 1991,351: 268 - 269.

[28] Ahrens M A \& Peters R H. Patterns and limitations in limnoplankton size spectra. Can J Fish Sci, 1991, 48: 1967 - 1978.

[29] Rodriguez J, Echevarria F \& Jimenez-Gomez F. Physiological and ecological scaling of body size in an oligotrophic, high mountain lake (La Caldera, Sierra Nev da, Spain). J Plankton Res, 1990,12 : 593 - 599.

[30] George D G \& Taylor A H. UK lake plankton and the Gulf Stream. Nature, 1995,378 : 139.

[31] Hart R C. Seasonality of aquatic invertebrate in low altitudes and Southern Hemisphere inland waters. Hydrobiologia, $1985, \mathbf{1 2 5}$ : $151-178$.

[32] Brandorff G O \& De Andrade E R. The relationship between the water level of the Amazon River and the fate of the zooplankton population in Lago Jacaretinga, a varzea lake in the central Amazon. Stud Neotrop Fauna Environ, 1978, 13: $63-70$. 